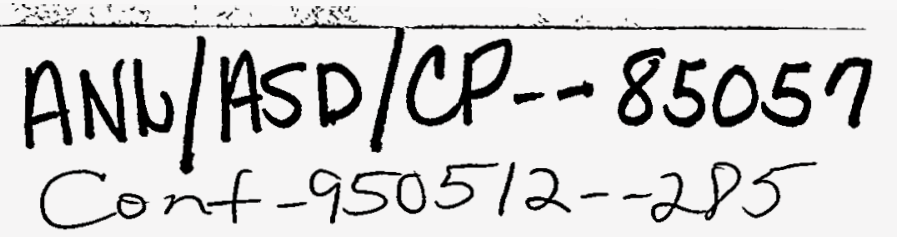

\title{
PERFORMANCE OF THE ADVANCED PHOTON SOURCE (APS) LINEAR ACCELERATOR*
}

\author{
M. White, N. Arnold, W. Berg, A. Cours, R. Fuja, J. Goral, A. Grelick, K. Ko, Y. L. Qian, \\ T. Russell, N.S. Sereno, and W. Wesolowski, Argonne National Laboratory, Argonne, IL 60439 USA
}

\section{Abstract}

A $2856-\mathrm{MHz}$ S-band, electron-positron linear accelerator (linac) is the injector and source of particles for the APS [1]. The linac is operated 24 hours per day, with $405-\mathrm{MeV}$ electrons to support commissioning of the other APS accelerators, and with positrons or electrons to support linac studies. It produces electrons with energies up to $655 \mathrm{MeV}$ or positrons with energies up to the design energy of $450 \mathrm{MeV}$.

\section{INTRODUCTION}

The design goal of the APS electron linac is to accelerate 30-nsec-long pulses containing $50 \mathrm{nC}$ of electrons to an energy of $200 \mathrm{MeV}$. The beam is focused to a $3-\mathrm{mm}$ diameter spot on a 7-mm-thick water-cooled tungsten target that serves as a positron converter. Pair produced positrons and electrons are refocused by a 1.5-T pulsed coil, and are directed into the positron linac where they are captured and accelerated to 450 $\mathrm{MeV} \pm 1 \%$. The design positron current is $8 \mathrm{~mA}$. To date, $1.45 \mathrm{~A}$ of electrons were accelerated to $225 \mathrm{MeV}$ at $30 \mathrm{~Hz}$ in the electron linac, and were focused to a $\leq 5-\mathrm{mm}$ diameter spot on the target. The linac was able to accelerate $9 \mathrm{~mA}$ of positrons to $285 \mathrm{MeV}$ within one week of the beginning of positron studies, and has since achieved a positron energy of $450 \mathrm{MeV}$ with an energy spread less than $\pm 1.6 \%$. Measured radiation levels near the linac are within DOE guidelines [2].

\section{EQUIPMENT DESCRIPTION}

Particles are accelerated in the linac by 14 SLAC-type accelerating structures, five in the electron linac and nine in the positron linac. The upstream accelerating structure in each part of the linac is directly powered by a $35-\mathrm{MW}$ klystron, while the remaining 12 structures are powered in groups of four by a klystron and a SLED cavity assembly, as shown in Figure 1. Power to the klystrons is provided by 100-MW line-type modulators. Recent upgrades to the modulators led to improved performance and reliability, and are described elsewhere [3].

The individual timing of each of the five pulse modulators is optimized to gain maximum energy from the available if power in each sector, and the timing of each of the three SLEDs is also individually optimized for maximum energy gain. The electron or positron beam is bent into the appropriate diagnostic line, and data on timing versus energy, interpreted from the beam position on a fluorescent screen, are taken and analyzed using sdds tools [4]. Timing is reoptimized after modulator upgrades and SLED retuning, and Figure 2 is an example of such a timing curve. Figure 3 is the diagnostic line at which the data were taken.
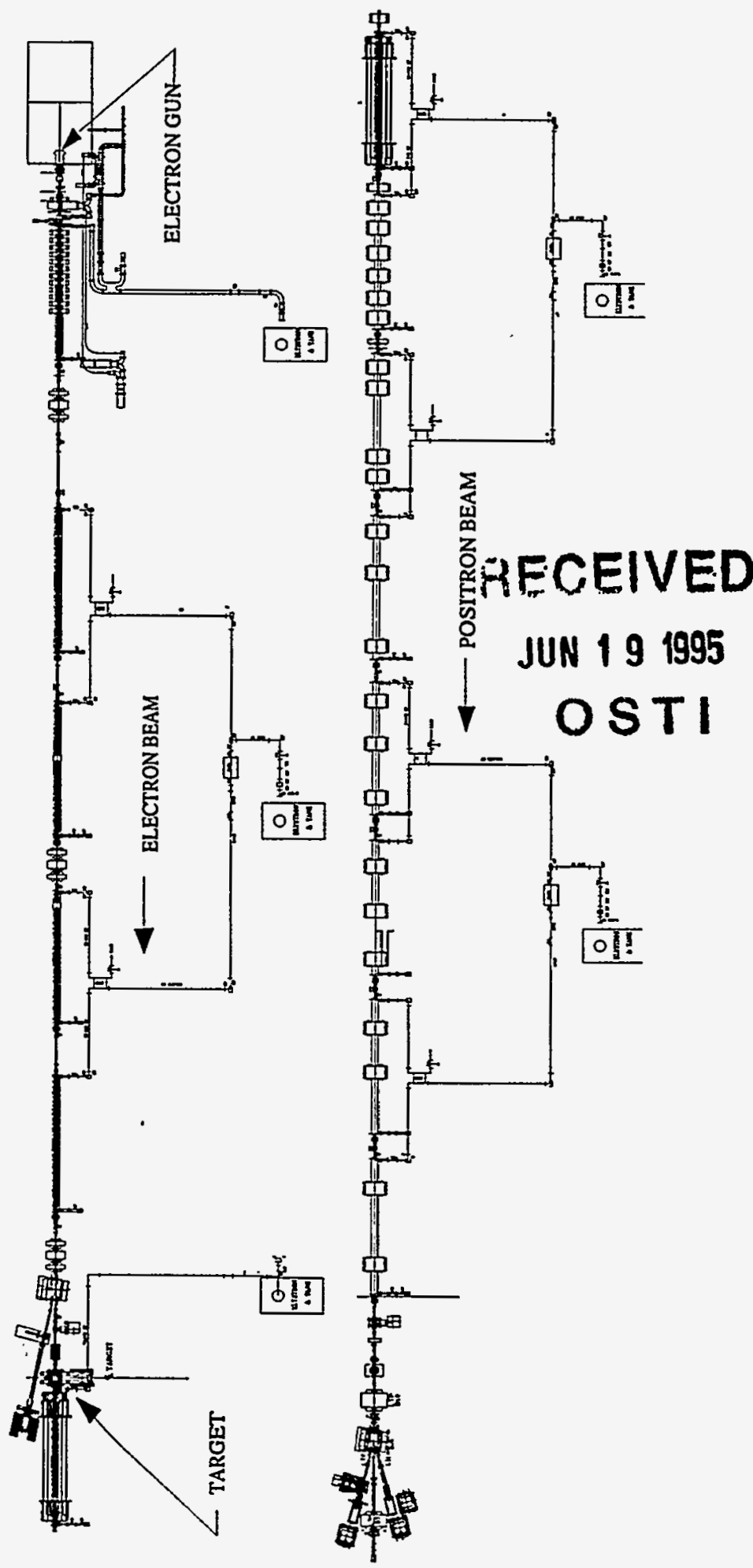

Figure 1: Overview of the electron and positron linacs.

- Work supported by the U. S. Department of Energy, Office of Basic Sciences under the Contract W-31-109-ENG-38. 


\section{DISCLAIMER}

Portions of this document may be illegible in electronic image products. Images are produced from the best available original document. 


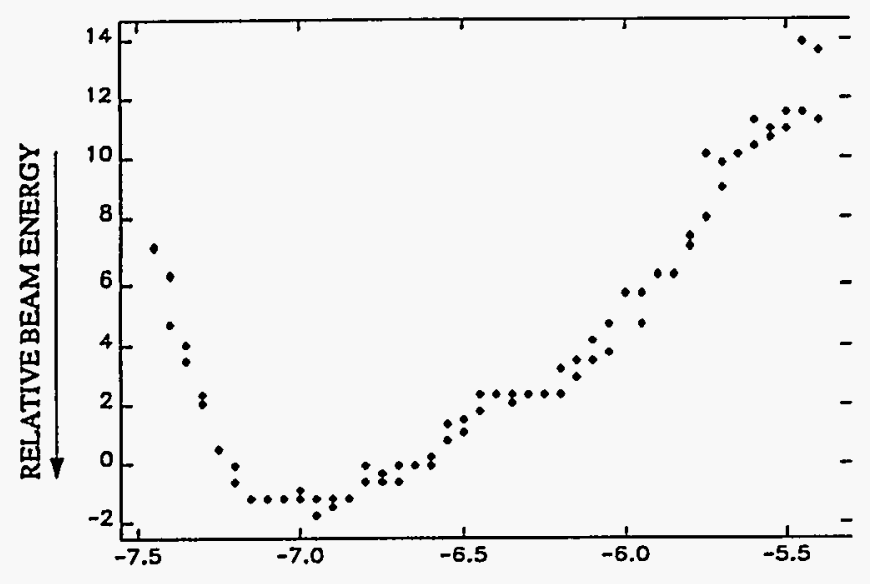

L4 MODULATOR TRIGGER TIME ( $\mu \mathrm{sec})$

Figure 2: Modulator (and SLED) timing optimizations are performed for each sector to optimize use of the modulator pulse and thus achieve maximum energy gain. These modulator timing data were collected using sdds tools [2].

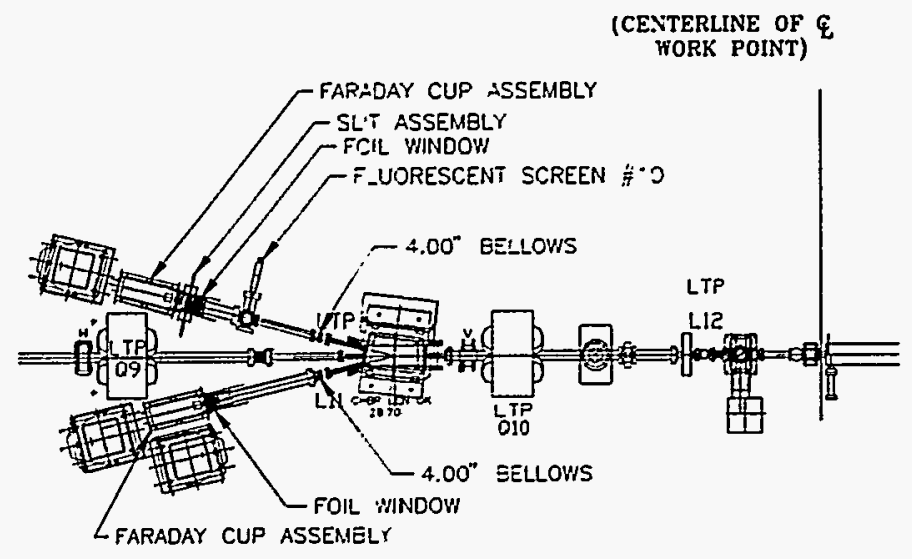

Figure 3: Positron linac diagnostic lines allow energy, energy spread, and phase optimization to be performed for electrons or positrons. Other beam parameters are also measured using information from equipment in this line.

A new beam position monitor (BPM) will be installed at the exit of the dipole magnet shown in Figure 3, and will allow continued development and eventual routine use of automated rf phase optimization programs.

The low-level If system has functioned well for more than a year and is described elsewhere in these proceedings, along with the existing automatic if phase control system that maintains constant phase (to within $\pm 2^{\circ}$ ) between the five klystrons [5].

Linac beam diagnostics include wall current monitors, BPMs [6], fluorescent screens [7], and loss monitors. The existing BPMs are unable to distinguish between positive and negative signals, so positron optimization must be done using BPMs in conjunction with other information. A new type of BPM currently under development will be able to make the distinction, and will facilitate positron tuning if successful [8]. Average current monitors are installed for the purpose of shutting down the linac in the unlikely event that the average electron current in either the electron linac or the positron linac becomes excessive. The quantity of each type of diagnostic in each section of the linac is listed in Table 1 . The beam's microbunch length has been measured by backphasing, and also by using a 5th-harmonic if cavity. Descriptions of the technique and the first results are found in [9].

Table 1: Linac Diagnostics.

\begin{tabular}{ccc}
\hline Type & \# in e- linac & \# in e+ linac \\
\hline average current mon. & 2 & 2 \\
wall current mon. & 3 & 1 \\
BPM & 5 & 5 \\
fluorescent screen & 3 & 5 \\
loss monitor & 5 & 9 \\
5th harmonic cavity & 1 & 0 \\
\hline
\end{tabular}

The linac is controlled by the Experimental Physics and Industrial Control System (EPICS) [10]. The system is extremely flexible and when combined with the sdds toolkit, provides a powerful environment for monitoring and control of the linac and its various systems. Figure 4 is an example of an EPICS control screen for the linac.

\section{PERFORMANCE} date.

Table 2 lists a summary of the linac's performance to Table 2: Linac Performance Summary.

\begin{tabular}{lcc}
\hline & Design Goal & Achieved \\
\hline Electron Linac & & \\
Energy on Target & $200 \mathrm{MeV}$ & $235 \mathrm{MeV}$ \\
Pulse Length & $30 \mathrm{~ns}$ & $30 \mathrm{~ns}$ \\
Target Spot Size & $\varphi \leq 3 \mathrm{~mm}$ & $\varphi \leq 5 \mathrm{~mm}$ \\
Power on Target & $480 \mathrm{~W}$ & $225 \mathrm{~W}$ \\
Current on Target & $1.7 \mathrm{~A}$ & $1.45 \mathrm{~A}$ \\
Repetition Rate & $48 \mathrm{pps}$ at a & $30 \mathrm{~Hz}$ \\
& $60-\mathrm{Hz} \mathrm{rate}$ & \\
Maximum Energy & $650 \mathrm{MeV}$ & $655 \mathrm{MeV}$ \\
Energy Spread & $\pm 8 \%$ & $\leq \pm 8 \%$ \\
Emittance & $\leq 1.2 \mathrm{~mm} \mathrm{mrad}$ & $\leq 1.2 \mathrm{~mm} \mathrm{mrad}$ \\
& & \\
Positron Linac & & \\
Output Energy & $450 \mathrm{MeV}$ & $458 \mathrm{MeV}$ \\
Output Current & $8 \mathrm{~mA}$ & $9 \mathrm{~mA}$ \\
Energy Spread & $\pm 1 \%$ & $\leq \pm 1.6 \%$ \\
\hline
\end{tabular}

\section{SUMMARY}

The APS linac has been operational for about a year, and has met most of its design goals. Considerable time was spent conditioning the high power if equipment, however conditioning is now excellent for most purposes. The design goal for positron current at the design energy has not yet been 


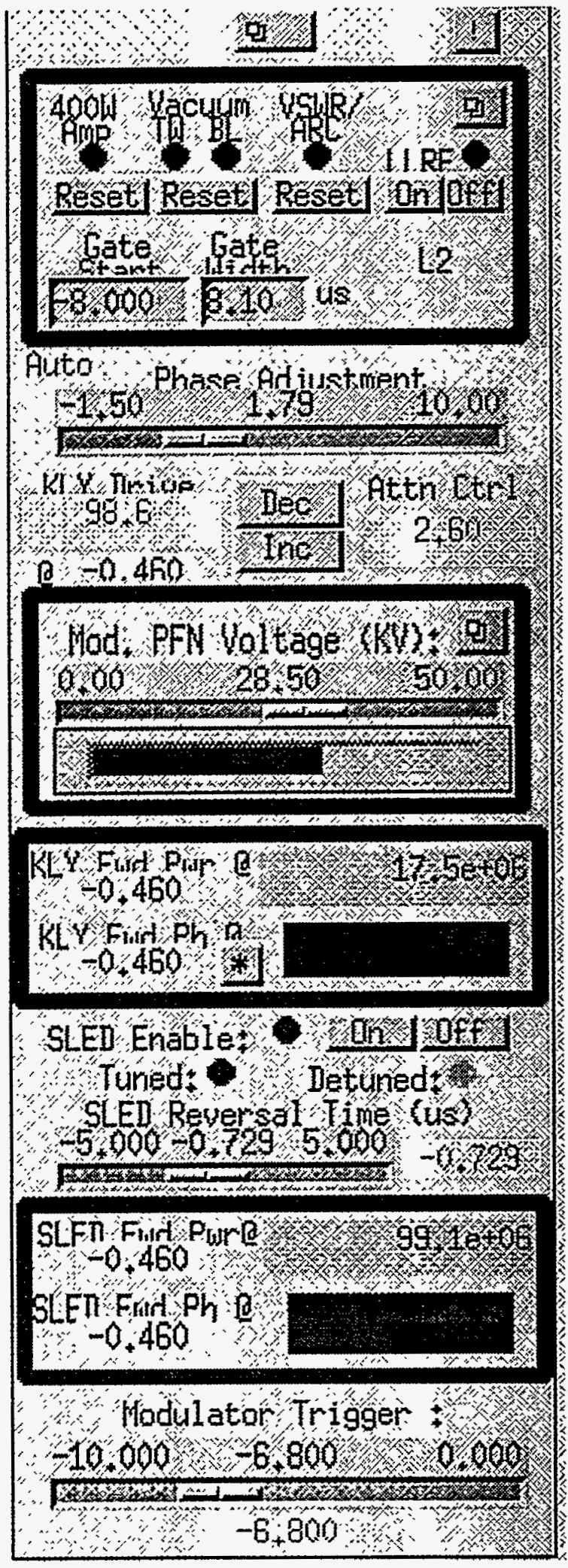

Figure 4: An example of a portion (20\%) of the linac if overview control screen. Rf power, timing, and phase information can be read out and modified from this screen. A limited set of faults can be reset directly. and a variety of "engineering screens" are accessible from pull down menus on this screen. met. By the time rf conditioning permitted $450-\mathrm{MeV}$ positron runs, the gun cathode performance had degraded significantly. The cathode is scheduled for replacement, and the design positron current at $450 \mathrm{MeV}$ will most likely be achieved during the first shift with the new cathode. The positron focusing system as well as some possible improvements to it are discussed in [11].

The linac operates 24 hours per day to produce $405-\mathrm{MeV}$ electrons for the purpose of commissioning the other APS accelerators. Positrons are used in linac and low energy transport line studies but, will soon be injected into the positron accumulator ring.

\section{Acknowledgments}

We gratefully acknowledge the efforts of $\mathrm{M}$. Douell, C. Gold, D. Jefferson, M. Lagessie, D. Meyer, T. Jonasson, S. Pasky, L. Peterson, and D. Yuen during construction and initial operation of the linac, and of D. Fallin for all of the drawings. We also appreciate the advice and experience of G. Mavrogenes.

\section{REFERENCES}

[1] 7-GeV Advanced Photon Source Conceptual Design Report, ANL-87-15, April 1987.

[2] H. J. Moe, et al., "Radiation Measurements at the Advanced Photon Source (APS) Linear Accelerator," these proceedings.

[3] T. Russell and A. Cours, "Klystron Modulator Operation and Upgrades for the APS Linac," these proceedings.

[4] M. Borland, "A Self-Describing File Protocol for Simulation Integration and Shared Postprocessors," these proceedings.

[5] A. Grelick, et al., "Phase Control and Intra-Pulse Phase Compensation of the Advanced Photon Source (APS) Linear Accelerator," these proceedings.

[6] R. E. Fuja and M. White, "Performance of the Advanced Photon Source (APS) Linac Beam Position Monitors (BPMs) with Logarithmic Amplifier Electronics," these proceedings.

[7] W. Berg and K. Ko, "Status of the Fluorescent Screens and Image Processing for the APS Linac," Beam Instrumentation Workshop Proc., Santa Fe, NM, Oct. 1993.

[8] W. Sellyey, private communication.

[9] N. Sereno, et al., "Bunch Length Measurements at the Advanced Photon Source (APS) Linear Accelerator," these proceedings.

[10] L. Dalesio, et al., "The experimental physics and industrial control system architecture: Past, present and future," Nucl. Instrum and Methods A 352, 179 (1994).

[11] Y. L. Qian and M. White, "Positron Focusing in the Advanced Photon Source (APS) Linear Accelerator," these proceedings. 


\section{DISCLAIMER}

This report was prepared as an account of work sponsored by an agency of the United States Government. Neither the United States Government nor any agency thereof, nor any of their employees, makes any warranty, express or implied, or assumes any legal liability or responsibility for the accuracy, completeness, or usefulness of any information, apparatus, product, or process disclosed, or represents that its use would not infringe privately owned rights. Reference herein to any specific commercial product, process, or service by trade name, trademark, manufacturer, or otherwise does not necessarily constitute or imply its endorsement, recommendation, or favoring by the United States Government or any agency thereof. , The views and opinions of authors expressed herein do not necessarily state or reflect those of the United States Government or any agency thereof. 